\title{
OS GRILHÕES DA ADMINISTRAÇÃO E DA GESTÃO EM INSTITUIÇÕES SUPERIORES PÚBLICAS DE ENSINO
}

THE HANDCUFFS OF ADMINISTRATION AND MANAGEMENT IN PUBLIC INSTITUTIONS OF HIGHER EDUCATION

\section{Wrana Panizzi \\ Universidade Federal do Rio Grande do Sul, Porto Alegre, RS, Brasil. Email:wrana@terra.com.br}

Recebido em: 29.02.2017 - Aceito em: 12.03.2017

\section{RESUMO}

Já faz algum tempo que a questão da administração e gestão das instituições de ensino superior fazem parte da pauta de um sem número de eventos e discussões acadêmicas. Neste sentido, no presente texto buscamos pensar essas duas categorias como campos semânticos diversos, mas não excludentes entre si, onde buscamos estabelecer algumas distinções entre aquilo que normalmente compete a administração pública, essa entendida como uma atividade ad tempore, e aquilo que diz respeito a gestão pública, essa, entendida como uma atividade pro tempore. Sobretudo, o que buscamos mostrar no decorrer do texto é que a tão anunciada ideia de autonomia universitária que, em tese, daria a universidade a liberdade de gerir-se como entidade autônoma não passa de um "prelado" constitucional que inexiste na prática em função de certo conjunto de mecanismos de controle construídos e impostos pela política neoliberal que engessam tanto a administração pública quanto a gestão das universidades.

PALAVRAS-CHAVE: Brasil, Administração Pública, Gestão Universitária, Instituições de Ensino Superior, Autonomia Universitária.

\section{ABSTRACT}

For some time now the issue regarding administration and management of higher education institutions has been part of the agenda of a number of academic events and discussions. In this sense, in the present essay we try to think of these two categories as diverse, but not mutually exclusive, semantic fields, seeking to establish some distinctions between what normally corresponds to public administration, understood as an ad tempore activity, and what concerns public management, which is understood as a pro tempore activity. Mostly, what we have tried to show throughout the text is that the much-vaunted idea of university autonomy 
which, in theory, would give the university the freedom to manage itself as an autonomous entity is nothing more than a constitutional "prelate" that does not exist in practice due to a set of control mechanisms built and imposed by neoliberal politics that halt both the public administration and the management of universities.

KEYWORDS: Brazil, Public Administration, University Management, Institutions of Higher Education, University Autonomy.

\section{INTRODUÇÃO}

Conta o mito de Prometeu ${ }^{1}$ descrito por Hesíodo que, este, filho do titã Jápeto com Clímene, era um desafiante constante à onipotência e onisciência de Zeus. Num célebre episódio descrito por Hesíodo relata-se que durante um banquete destinado a selar a paz entre mortais e imortais, Prometeu foi responsável por aplicar um estratagema em Zeus ${ }^{2}$, ao colocar duas oferendas diferentes diante do deus olímpico. A primeira delas consistia de uma seleção de carne escondida dentro de um estômago de boi (alimento escondido dentro de um exterior repulsivo). A segunda, consistia nos ossos do boi totalmente envoltos em "reluzente gordura" (algo impossível de ser consumido dentro de um exterior atraente).

Diante dessas duas oferendas a ele oferecidas por Prometeu, Zeus escoIheu a segunda o que abriu precedente para os futuros sacrifícios de modo que, a partir de então, os humanos passaram a ficar e se alimentar com carne dos animais que sacrificavam dedicando aos deuses apenas os ossos, estes, envoltos numa camada de gordura como no embuste feito por Prometeu a Zeus. Tal estratagema deixou o onipotente deus olímpico enfurecido. Zeus, por sua vez, com vistas a punir os humanos por aquilo que lhes passou a oferecer (ossos envoltos em gordura) retirou o fogo dos humanos em retribuição ao pedantismo destes em Ihes oferecer aquilo que não Ihe servia como alimento como o fizera Prometeu.

Prometeu, por sua vez, novamente resolve desafiar ao referido Deus olímpico e rouba o fogo de Zeus dentro de um gigantesco caule de funcho, devolvendo, este, a humanidade. com vistas a punir a humanidade, Zeus Ihes enviou Pando$\mathrm{ra}^{3}$, esta, forjada por Hefesto4 a partir do barro e trazida à vida por obra dos quatro

1 Apresentado pela primeira vez nos 507 a 616 da Teogonia de Hesíodo.

2 Versos 545 a 557 da Teogonia de Hesíodo.

3 A primeira mulher, para viver com os homens, como constam nos versos 590 a 593 da Teogonia de Hesíodo, que "Dela descende a geração das femininas mulheres" e que trazem consigo a "a funesta geração e grei das mulheres, grande pena que habita entre homens mortais, parceiras não da penúria cruel, porém do luxo".

4 Filho de Zeus e Hera, rei e rainha dos deuses ou, de acordo com alguns relatos, apenas de Hera. Este, tido como o deus da tecnologia, dos ferreiros, dos artesãos, dos escultores, dos metais, da metalurgia, do fogo e dos vulcões. 
ventos de modo que todas as deusas do Olimpo reuniram-se para adorná-la.

Prometeu por sua vez, como castigo eterno, foi acorrentado a uma rocha no Cáucaso, onde seu fígado era devorado cotidianamente por uma águia, apenas para que Prometeu o visse regenerar-se durante a noite, segundo a lenda, devido à sua imortalidade 5 . Sendo que, somente anos mais tarde, o herói grego Héracles abateria a águia e libertaria Prometeu de seus grilhões.

Tal alegoria aqui apresentada nos serve como um estratagema para pensar a administração e a gestão pública ao longo do último meio século e o modo como o Estado brasileiro - nosso onipotente Zeus - ora por interesse próprio e com vistas a implementação de sua política neoliberal, ora por ocasião da meta-agenda internacional ligada, ao Banco Mundial (BM), Fundo Monetário Internacional (FMI) e a Organização de Cooperação e de Desenvolvimento Econômico (OCDE) pautaram a forma como as instituições públicas, em especial, as universidades deveriam estar estruturadas em termos administrativos, políticos e financeiros.

Mas, também o modo como, este mesmo Estado, tem punido ao povo brasileiro, os servidores públicos e grande parte dos trabalhadores do setor privado com o constante aumento de impostos em função do crescimento desenfreado da dívida pública. Mas não só, também puniu aos administradores públicos e a universidade com a criação de um falso binômio estruturante que separa - e serve aos propósitos utilitaristas do Estado de desmonte da Universidade Pública - a ideia de administração e gestão públicas de modo que, a primeira é visceralmente devorada pela segunda - como prometeu e sua águia - a cada vez que recebe recursos que se vinculam a determinadas rubricas e gastos ou ainda, a acordos políticos que, na maioria dos casos, senão na sua totalidade, engessam a administração pública e põe em derrocada a autonomia conferida a universidade que, na Constituição de 1988 eleva, a autonomia das universidades ao nível de princípio constitucional, como dispõe o Artigo 207, onde lê-se que:

"Art. 207 - As universidades gozam de autonomia didático-científica, administrativa e de gestão financeira e patrimonial, e obedecerão ao princípio da indissociabilidade entre ensino, pesquisa e extensão".

Contudo, por se tratar de preceito constitucional impede que a lei ordinária a ordene e the dê tangibilidade através de lei ou regulação específica como sustenta a jurista Anna Candida da Cunha Ferraz ${ }^{6}$. Dito isto, iniciamos o texto com

5 Contudo, com avanço da ciência e da medicina descobriu-se que o fígado é um dos poucos órgãos humanos que tem a capacidade de regenerar-se após determinadas lesões.

6 Para maiores detalhes ver "A Autonomia Universitária na Constituição de 05.10.1998”disponível em: http:// www.pge.sp.gov.br/centrodeestudos/revistaspge/revista/tes5.htm 
uma primeira parte onde buscamos estabelecer algumas distinções entre aquilo que normalmente compete a administração pública, essa entendida como uma atividade ad tempore, e aquilo que diz respeito a gestão pública, essa, entendida como uma atividade pro tempore.

A essa distinção que nessa primeira parte fazemos entre uma e outra, seguese uma segunda parte, onde, através de documentos legais trazemos a baila 0 modo como tanto a meta-agenda neoliberal que pautou a política nacional quanto a meta-agenda construída pelos organismos internacionais supra-referidos (Banco Mundial, Fundo Monetário Internacional e a e a Organização de Cooperação e de Desenvolvimento Econômico) orientaram a construção e a elaboração de uma série de políticas que quase levaram ao desmantelamento de todo sistema público de ensino superior no Brasil.

Movimento esse que teve certo compasso com essa meta-agenda e que, pode, claramente ser dividido para fins dessa explanação em três momentos distintos, a saber: 1) da instauração da política neoliberal (anos de 1980); 2) de ampliação e instrumentalização da política e do consequente sucateamento da universidade (anos de 1990); e, 3) da mercantilização da universidade e do ensino público (a partir dos anos 2000). E, onde, a partir de uma retomada histórica buscamos colocar em evidência as diferentes nuanças que permearam o modo como a questão da administração e da gestão públicas eram pensadas no interior da universidade tanto por seus gestores e administradores quanto por parte de estado brasileiro, esse, mantenedor daquelas.

Contudo, há de se colocar no texto, um ponto final. Todavia, isso não significa que a discussão ali se encerra mas que, como fazemos nas considerações finais, nesta, sistematizamos nossos achados e inquietações que poderão - num futuro não tão distante, se a oportunidade convir - inspirar outras discussões mais aprofundadas.

\section{DO PROMETEU ACORRENTADO E A ÁGUIA QUE O DEVORA: ADMINIS- TRAÇÃO E GESTÃO PÚBLICA EM PERSPECTIVA COMPARADA}

Urucubaca, mandinga

Ataca, mexe e me xinga Esquenta e racha a moringa

Até que o leite azedou

Bochecha inchada na raça 
Araçá, coentro e cachaça

O berimbau tem cabaça

E um som que é "deep in my soul"

(Raul Seixas - Tapanacara - 1977)

Toda e qualquer organização/instituição, seja ela pública ou privada, necessita no desenvolver de sua atividade-fim a presença de profissionais capazes de gerenciar seus recursos humanos e financeiros, mas também, que sejam capazes de pensar e organizar sua estrutura com vistas a consolidação da participação da organização/instituição no âmbito tanto do mercado em si quanto do Estado com vistas a promover o seu crescimento e o cumprimento de sua missão.

Todavia, para que isso ocorra se faz necessário que haja, dentre os recursos humanos disponíveis no âmbito de tal organização/instituição profissionais capazes de realizar tais funções com vistas a que haja, sempre, uma otimização e uso mais eficiente dos recursos disponíveis, sempre levando em consideração as questões legais que implicam determinadas decisões e o uso de diferentes tipos de recursos disponíveis. $\mathrm{E}$, nesse sentido, no que se refere ao caso específico das instituições de ensino superior públicas tem-se que esse profissional, para além da execução técnica de determinadas rotinas administrativas deve também, no âmbito decisório considerar a existência de diferentes políticas públicas que condicionam e normatizam a atividade-fim da instituição e que devem, sempre considerar os desejos e as necessidades da sociedade.

Basicamente, estamos falando portanto de funções-chave a serem desempenhadas no interior de uma dada instituição, quais sejam: a de administrador e a de gestor. Contudo, é necessário, antes de mais nada que realizemos uma breve distinção entre aquilo que se esperar desses dois profissionais. Desta feita, temse que quando estamos falando de administração pública (e consequentemente de administradores) estamos fazendo referência a um profissional mais generalista, executivo, que se ocupa dos aspectos mais gerais relacionadas a esta e que, necessariamente, deve dominar minimamente vários campos do saber tais como a gestão de recursos, a gestão contábil, a gestão de pessoas etc., um profissional que deve coordenar equipes e orientar cada um dos gestores ligados as diferentes áreas disciplinares na execução de suas atividades-fim sendo, este, um profissional que atua ad tempore e de modo independente em relação aos gestores, os quais, possuem cargos que têm um prazo determinado e atuam pro tempore na execução de suas atividades-fim. 
$E$, nesse sentido, quando falamos de cargos executivos vinculados a administração das instituições de ensino superior públicas como é caso, por exemplo, das funções comissionadas de reitor, vice-reitor, pró-reitores, vice-reitores, diretores de institutos e faculdades, chefias de departamento e/ou comissões, estamos nos referindo a gestão pública e a um tipo de profissional que possui um conhecimento mais especializado, focado em determinadas áreas do saber e/ou setores da administração pública, em especial, no que tange a gestão de recursos públicos repassados a instituição pela administração federal.

Pensadas do ponto de vista sistêmico, tem-se que a administração pública e o profissional de administração que atua em uma universidade tem como campo de atuação um macrossistema de contas, recursos e pessoal que deve coordenar e gerir, enquanto que, o gestor se ocupa de microssistemas mais especializados vinculados a um determinado saber, este, mais especializado que o primeiro. Sendo assim, tem-se que tanto a administração pública quanto a gestão pública, de um modo geral: 1) se utilizam de um mesmo conjunto de técnicas, metodologias e práticas; 2) que compartilham objetivos comuns em relação a atividade-fim da instituição; e, 3) exigem dos profissionais que executam tais atividades-fim características e atitudes parecidas.

Contudo, as semelhanças param por aí de modo que as diferenças entre o exercício de uma e outra função são notórias e exigem saberes diversos na medida em que administrar exige um conhecimento mais abrangente e executivo de todas as áreas da gestão pública, enquanto, esta, a segunda exige um conhecimento mais técnico e especializado como por exemplo, o conhecimento das legislações orçamentárias e tributárias, das licitações, das políticas públicas, da responsabilidade social e civil pública etc.

Também são diversos na medida em que o administrador possui uma formação mais global enquanto que o gestor, não necessariamente precisa ter essa formação, mas sim, ser hábil em pensar estrategicamente o modo como diferentes recursos serão alocados e gerenciados pela instituição de modo que, a gestão, se caracteriza por um olhar bem mais acurado e específico que busca colocar em prática, através de sua atividade-fim, determinados objetivos vinculados a administração federal e que se direcionam sempre para determinados propósitos de ordem social e governamental que Ihes são impostos/exigidos tanto internamente (no âmbito do seu plano de desenvolvimento institucional - PDI) quanto externamente (no âmbito das exigências e regulações existentes a nível da administração pública federal em relação a suas atividades-fim), como já escrevemos em outro lugar (PANIZZI e MEIRELLES, 2014). 
Nesse sentido e em função do exposto tem-se então que, na atualidade, o grande problema a ser enfrentado no âmbito das instituições de ensino superior públicas no Brasil reside, sobretudo, em se pensar a gestão de uma universidade que tem autonomia por força de lei (Art. 207 da CF/1988), mas que na prática se encontra acorrentada a um modelo de estado que pensa a universidade como funcional (CHAUÍ, 2003; PANIZZI, 2006) e voltada ao cumprimento das necessidades do mercado que pautados no modelo neoliberal, pensam a educação como um produto a ser consumido e a universidade como cortesã servil das necessidades de um modelo econômico que, ao mesmo tempo que exige desta a formação de um profissional hiper-especializado (PANIZZI e MEIRELLES, 2013), a precariza, corta recursos e engessa a gestão universitária a partir de um sem número de regulações e políticas que, grosso modo, tornam impraticável a tarefa de gerir a universidade de forma autônoma e não tutelada como ocorre atualmente.

Políticas e regulações essas que, como veremos a seguir, estão pautadas numa meta-agenda nacional e internacional que, pelo menos ao longo do último meio século têm orientado nossos governantes (e em consequência a administração pública federal) a partir de uma perspectiva canhestra e perversa que culpabiliza a gestão universitária (e consequentemente seus gestores) pelos problemas enfrentados por essas instituições desde muito tempo através de construções tais como: "Professores não sabem administrar.", "Lugar de professor é na sala de aula e não na Reitoria.", "Que a gestão da Universidade deveria ser feita por administradores e não por professores." etc. Eis aí, aquilo que está no deep in my soul, parafraseando o profético Raul Seixas, da administração federal desde o momento em que, essa, se curvou aos interesses do mercado e aos ditames do neoliberalismo globalizado.

\section{DOS GRILHÕES DE PROMETEU: A UNIVERSIDADE PÚBLICA E A META-A- GENDA NACIONAL E INTERNACIONAL}

A solução pro nosso povo eu vou dar Negócio bom assim ninguém nunca viu

Tá tudo pronto aqui é só vir pegar A solução é alugar o Brasil! Nós não vamos pagar nada Nós não vamos pagar nada

É tudo free, 
Tá na hora agora é free, vamo embora

Dar lugar pros gringo entrar

Esse imóvel tá pra alugar (Raul Seixas - Aluga-se - 1980)

É, pois no contexto do pós-guerra que marca a segunda metade do século passado, que os Estados Nacionais se reorganizaram com vistas a sua reestruturação e o aproveitamento das condições necessárias a sua operacionalização garantindo à ação pública um conjunto de instrumentos capazes de viabilizar a concretização de seus propósitos últimos, ou seja de sustentação e consolidação do sistema macroeconômico em surgimento e instauração de uma relação - construída politicamente - que dividiu o mundo entre países pobres e ricos, desenvolvidos e subdesenvolvidos, centrais e periféricos.

Instituiu-se assim, um novo "aggiornamento" global que, pautado nos preceitos de uma política neoliberal que - a partir do final dos anos 1980 foi empregado por uma ampla variedade de estudos acadêmicos, em especial aqueles voltados aos campos da economia política e da economia do desenvolvimento, em substituição e/ou como equivalente semântico a outros termos anteriormente utilizados, tais como monetarismo, neoconservadorismo, Consenso de Washington ou "reforma do Estado" etc., o qual trouxe consigo uma série de ideias e formas de pensar o Estado derivadas do capitalismo laissez-faire que, pautadas nos preceitos do liberalismo clássico, começaram a ser implementadas a partir do início dos anos 1970 e 1980 - acabou por reconfigurar todo o modo de produção capitalista mundial e o modo como, o Estado, deveria relacionar-se com o mercado e a economia na medida em que o mote deste novo sistema produtivo residia em políticas de liberalização econômica que advogavam em favor das privatizações, da austeridade fiscal, da desregulamentação, do livre comércio e do corte de despesas governamentais com o consequente reforço do papel do setor privado na economia.

Neste sentido, tem-se que o capitalismo globalizado resultante das transformações dos sistemas produtivos, das novas configurações territoriais e da formação e consolidação dos agentes políticos e institucionais estabelecidos e reunidos em torno de objetivos comuns - locais e internacionais vigentes, de recuperação econômica construídos na perspectiva de enfrentamento dos desafios do novo tempo em instalação, tais como o BM, FMI, OCDE e OMC - implicou na construção de certo conjunto de diretrizes que devem ser seguidos pela maioria dos 
países que, alinhados ou não a tais interesses, buscavam inserção num mercado, agora, pensado em escala mundial.

Em função disso, nota-se que as propostas de desenvolvimento apresentadas encontraram no neoliberalismo (e, aqui no seu sentido de liberalismo clássico de Adam Smith) em estabelecimento e transformação, os princípios e as bases conceituais fundantes das políticas a serem adotadas, as quais, passaram a ser orientadoras dos planos, programas e projetos em construção. Princípios estes, manifestos na construção de uma meta agenda pautada em princípios liberais e do livre mercado. Esta, um lócus privilegiado onde residiu - e ainda se mantem viva a partir desta - a fonte do pensamento ideológico neoliberal - base e parâmetro - para ver e julgar o mundo social e para promover o equacionamento de seus desafios e tornar a sociedade uma instância mais racional, eficiente e produtiva como quer o liberalismo clássico.

Com o propósito de buscar essa inserção no interior de um mercado global e, também, garantir seu lugar ao sol no seio desde novo modelo econômico que se tornava realidade, tem-se que a maioria dos Estados Nacionais acabam - com vistas a pensar, financiar e adequar sua reestruturação a esse novo sistema econômico global - por recorrer a um conjunto de organismos multilaterais, entre eles os acima citados, no sentido de encontrar nos mesmos, não só a orientação e as bases conceituais - metodológicas necessárias e as diretrizes imprescindíveis à elaboração de propostas, programas e a instrumentação da intervenção e de base delineadora às medidas de intervenção e políticas destinadas a busca e a promoção do desenvolvimento destes diferentes países.

Trata-se, portanto, de um movimento que "aggiornou" países dotados de grandes dificuldades econômicas, sociais, culturais, mas também, que ajudou a construir a fixar uma relação de subalternidade entre países ricos e pobres, desenvolvidos e subdesenvolvidos, centrais e periféricos, onde, caberá aos primeiros nortear e difundir os novos processos e concepções de desenvolvimento tidas como mais adequadas a inserção dos segundos nesse sistema econômico de escala global. Espaço este, de assimetrias e desigualdades, a partir do qual é constituída uma meta agenda norteadora do modo como o estado deve agir, intervir e/ ou comportar-se no que se refere ao seu papel de agente regulador do mercado, da economia, dos sistemas de saúde, educação, saneamento etc.

Locus de atuação este que tem no Banco Mundial, por exemplo, o sistema de referência para a construção de políticas e projetos governamentais ligados ao

7 Refere-se a ideia de "aggiornamento". 
financiamento da infraestrutura tida como necessária para o seu desenvolvimento. Sobretudo, no presente estudo nos interessa colocar em destaque e examinar a ação do Banco Mundial no que se refere as suas propostas de atuação. Isto é, que setores e que campos de ação a agência considera fundamentais e efetivamente capazes de incidir na realidade do desenvolvimento dos países. Que aspectos são capazes de transformar a realidade econômica e social das diferentes nações: Como, de que forma e com quais instrumentos - a partir das suas reais demandas - é possível uma ação efetiva.

Entretanto, cabe aqui um parênteses para uma observação: o texto em questão tem como foco o exame da administração e da gestão de instituições públicas e se ocupa especificamente das instituições públicas de educação superior ${ }^{8}$. Contudo, não podemos negar que haja no interior destas instituições - tanto no que se refere a administração quanto a gestão universitária - certa influência exercida pelo Banco Mundial. Influência essa não direta, mas indiretamente produzida a partir de análises e escritos teóricos, de dados quantitativos apresentados em diferentes estudos que, quer queiramos, quer não, acabam por permear as decisões administrativas e de gestão em função da vivência e diálogo que acabamos tendo com outros reitores $^{9}$ - que regularmente encontravam-se reunidos em diferentes instituições representativas e colegiadas: A UNESCO, OEI,AULP, AUGM, CEXECI e Andifes ${ }^{10}$.

Ainda, o tema tem sentido para a área de estudos e para o público a quem está revista está dirigida dada a importância estratégica da educação - no caso aquela de caráter superior (universitária) - para o desenvolvimento das nações. Premissa esta fortemente dirigida e legitimada por dirigentes políticos ${ }^{11}$, as lideranças econômicas e sociais, os acadêmicos, os empresários os trabalhadores e a sociedade em geral como é caso, por exemplo, do Grupo Gerdau, Fundação Roberto Marinho, da Fundação Ayrton Senna, da Fundação Itaú do Movimento todos pela Educação,etc... Apesar de objetivos e concepções diversificadas, seja de conceituação e de papel da educação como por exemplo: educação bem público e social versus educação bem de capital; educação como fonte de riqueza cultural e de valor civilizatório versus educação como riqueza material.

8 É certo que o Banco Mundial age em diferentes campos, indo das questões macroeconômicas, das financeiro -administrativas às sócios culturais, dado a importância estrutural das mesmas e suas interelações.

$9 \mathrm{Em}$ especial, refiro-me ao período que exerci atividades de gestão colegiada junto a UFRGS, assim como, ao período que antecedeu e se sucedeu aos meus dois mandatos como representante máximo da instituição. 10 Organização das Nações Unidas para Educação, Ciência e Tecnologia; Organização dos Estados Ibero-Americanos; Associação das Universidades de Língua Portuguesa; Associação das Universidades do Grupo Montevideo; Extremeño de Estudios y Cooperación con Iberoamérica; Associação Nacional dos Dirigentes das Instituições Federais de Ensino Superior

11 Como mostram diversos programas e ações desenvolvidas pelo Ministério da Educacão (MEC), disponíveis em: http://portal.mec.gov.br/sesu-secretaria-de-educacao-superior/programas-e-acoes 
Neste sentido, centrada na educação as ações do Banco Mundial passaram por diferentes prioridades em momentos distintos. Dos anos 1960 até o fim do século XX o apoio à educação se estendeu aos investimentos em infraestrutura técnica e educação de nível médio e vocacional (cursos técnicos: sistema S), até se fixar nas necessidades básicas dos mais pobres - moradia, saúde, alimentação e educação - com a aprovação e centralização da meta na educação básica estabelecida em 1990, durante a Conferência Mundial de Educação para Todos, realizada em Jontiem - Tailândia.

Neste último, a partir da leitura de seus documentos, destaca-se o compromisso de se priorizar a educação básica com vistas a se diminuir a pobreza por meio da melhoria da educação ofertada. Movimento esse que, a partir de então contaria com recursos específicos destinados a educação básica e a participação financeira dos demais setores da sociedade. Tais como as grandes empresas e suas organizações patronais: FIERGS, FAPESP, CNI, etc ${ }^{12}$

Assim, nesta perspectiva de geradora de bens, ainda que diferenciados, o que se vislumbrava é que a educação tinha como papel o de promover a inclusão do indivíduo na sociedade, mesmo que de forma subalterna e inserida em novos e diferentes mecanismos de hierarquia e novas formas de exclusão construídas e diluídas ao longo do processo de escolarização e de produção da vida social ${ }^{13}$. Contudo, fica a pergunta: qual inclusão social queremos? Quais são os moldes dessa inclusão? A que objetivos e interesses servem tal inclusão?

Ainda, no que se refere ao exame das propostas do Banco Mundial ${ }^{14}$ o que se verifica é que a estabilidade econômica dos países em desenvolvimento tem nas questões sociais (leia-se educação) a sua base, a sua essência conforme dito pelo presidente da instituição, em discurso em 1999 quando este colocou que:

[...] justiça social é uma questão tão importante quanto crescimento econômico. A curto prazo você pode manter a desigualdade. Mas a longo prazo não dá para ter uma sociedade estável [...]. É necessário criar oportunidades para que as pessoas pobres se desenvolvam, investindo em educação e em reforma agrária ${ }^{15}$.

12 Federação das Indústrias do Estado do Rio Grande do Sul; Fundação de Amparo à Pesquisa do Estado de São Paulo; Conferência Nacional da Indústria.

13 Ver Altmann e Bourdieu (1998).

14 El financiamento de la educación em los países em desarrollo: opciones de política (1986); Eduación primaria (1992); Lo que el trabajo requiere de las escuelas; Prioridades y estratégias para la educacion - estudo sectorial del Banco Mundial (1995); La enseñanza superior: las lecciones derivadas de la experiência (1995); El Estado em um mundo em transformación (1997);

15 Wolfensohn, James D. (1999, January 1). A proposal for a comprehensive development framework A discussion draft. Washington, DC: World Bank. Available on line at http://www.worlbank.org/cdf 
Isso, ainda acrescido da observação - de que "a educação é tratada pelo Banco como medida compensatória para proteger os países e diminuir as possíveis tensões no setor social", conforme assinala Marília Fonseca ${ }^{16}$. Desta feita, tem-se que com a escolha da educação básica como centro da atuação política e das estratégias institucionais o que é possível aferir do conjunto dos documentos oficiais do Banco Mundial, corroborado e com o aval das parcerias e das visões de outras importantes agências internacionais, é que este construiu e passou a defender uma articulada e ampla proposta de trabalho.

Esta, difundida junto aos diferentes governos e países a partir de seus dirigentes políticos e do estabelecimento de meta agendas nacionais que seguiam os preceitos impostos pela ação e a meta agenda proposta por diferentes organismos internacionais de financiamento e apoio ao desenvolvimento dos países de economia periférica, a qual, passou a ser seguida e implementada pelos dirigentes políticos e pelas lideranças das mais diferentes e distintas regiões do planeta.

A proposta e seus desmembramentos, de acordo com os objetivos propugnados pelo Banco Mundial se expressaram, assim, em um conjunto de ações e políticas que deveriam ser seguida em âmbito global a partir de uma meta agenda comum a todos os países, a qual, tinha como foco a melhoria dos sistemas educacionais. Resumidamente, tais proposições podem ser sintetizadas nos seguintes objetivos/metas por este propugnados a partir do investimento nos seguintes eixos de ação, a saber:

a. prioridade para a educação básica;

b. melhoria de qualidade e da eficácia da educação, como foco da reforma educacional;

c. prioridade para os aspectos financeiros e administrativos da reforma educacional;

d. descentralização e instituições escolares autônomas e responsáveis por seus resultados;

e. convocação a uma maior participação dos pais e da sociedade nos temas relativos à educação;

f. reforço ao papel do setor privado e não governamental nas atividades educacionais (decisões e implementação);

g. mobilização e alocação de recursos adicionais aos projetos educacionais;

16 Ver, O Banco Mundial e a educação brasileira: uma experiência brasileira: uma experiência de cooperação internacional (1998). 
h. ênfase nos aspectos setoriais (alguns) da educação;

i. definição de políticas e estratégias com base em critérios de análise econômicos.

Não há dúvida de que "as lições" do Banco Mundial foram apreendidas em um grande conjunto de países, com destaque para os da América Latina e o Brasil, com os seus planos educacionais ${ }^{17}$. Os planos governamentais - suas metas - agendas nacionais - tornaram-se importantes instrumentos e discursos assimilados como uma verdadeira "panaceia" destinada a "salvar", a "esperançar" e a promover o desenvolvimento das nações e a mobilização de governos, segmentos da sociedade civil, estudiosos e acadêmicos. $\mathrm{E}$, mais do que isso, fizeram parte das prioridades das políticas nacionais levadas a cabo em um bom número de países nesses últimos anos ${ }^{18}$.

A incorporação desses ideais em políticas e programas adotados não só no Brasil como também em inúmeros países tem se apresentado de diferentes formas e de acordo com suas respectivas especificidades e demandas locais. No Brasil, as políticas de programas voltados a oferecer concretude e tangibilidade a essas diretrizes e normativas, presentes nesta meta agenda internacional se expressam em um grande conjunto de ação programática. O quadro abaixo busca sumariar e ilustrar algumas dessas iniciativas construídas e implementadas no contexto das políticas educacionais brasileiras.

Quadro 1 - Eixos de ação propostos pelo Banco Mundial e políticas e ações correlatas implementadas no Brasil

\begin{tabular}{|c|c|}
\hline EIXO DE AÇÃO & POLÍTICA/AÇÃO CORRELATA \\
\hline $\begin{array}{c}\text { a) prioridade para a educação } \\
\text { básica }\end{array}$ & $\begin{array}{l}\text { Retenção de recursos constitucionalmente } \\
\text { destinados a educação básica e superior, assim como } \\
\text { sua universalização (Ver Art. } 212 \text { da Constituição } \\
\text { Federal de } 1988 \text { e o Art. } 60 \text { da Lei n } 9394 / 1996) \text {. }\end{array}$ \\
\hline
\end{tabular}

17 Ver Mary Guimarães Nogueira, Ajuda externa para educação brasileira: da USAID ao Banco Mundial (1999); Maria Abádia da Silva, Intervenção e consentimento: a política educacional do Banco Mundial e as políticas educacionais (1996); Aurélio Vianna Jr. (Org.). A estratégia dos bancos multilaterais para o Brasil (1998); Marília Fonseca, O Banco Mundial e a educação: reflexões sobre o caso brasileiro (1995). O Banco Mundial e as políticas educacionais (1996); Aurélio Vianna Júnior. (Org.) A Estratégia dos bancos multilaterais para o Brasil (1998); Marília Fonseca, O Banco Mundial e a educação: reflexões sobre o caso brasileiro (1995).

18 Ver artigo ALTMANN, Helena. Influências do Banco Mundial no projeto educacional brasileiro. Em especial a parte dois "Convergências entre propostas do BIRD e a educação brasileira (2002). 


\begin{tabular}{|c|c|}
\hline EIXO DE AÇÃO & POLÍTICA/AÇÃO CORRELATA \\
\hline $\begin{array}{l}\text { b) melhoria de qualidade e da } \\
\text { eficácia da educação, como foco } \\
\text { da reforma educacional }\end{array}$ & $\begin{array}{l}\text { - Incentivo a formação e treinamento de professores, } \\
\text { vem como a criação de sistemas e programas de } \\
\text { avaliação nacionais dos diferentes níveis de ensino } \\
\text { tais como a Prova Brasil, o ENEM, o ENADE etc. } \\
\text { (Ver Art. } 62 \text { da Lei } n^{\circ} 9394 / 1996 \text { e, também, Art. } 68 \\
\text { a } 70 \text { ). }\end{array}$ \\
\hline $\begin{array}{l}\text { c) prioridade para os aspectos } \\
\text { financeiros e administrativos da } \\
\text { reforma educacional }\end{array}$ & $\begin{array}{l}\text { - Gestão de recursos, responsabilidade fiscal, } \\
\text { descentralização administrativa dos diferentes níveis } \\
\text { e sistemas de ensino e sua respectiva alocação de } \\
\text { recursos (Ver Art. } 211 \text { da Constituição Federal de } 1988 \text { e } \\
\text { Lei n } 9394 / 1996, \text { Art. } 8 \text { a 20, e também, os Art. } 68 \text { a 70). }\end{array}$ \\
\hline $\begin{array}{l}\text { d) descentralização e instituições } \\
\text { escolares autônomas e } \\
\text { responsáveis por seus resultados }\end{array}$ & $\begin{array}{l}\text { - Criação de orientações e bases nacionais comuns } \\
\text { para o ensino básico e técnico-profissionalizante } \\
\text { (Lei n } 9394 / 1996, \text { Art. 26); } \\
\text { - Implementação da ideia de autonomia universitária } \\
\text { (Ver Art. } 207 \text { da Constituição Federal de 1988); e, } \\
\text { - Implementação de sistemas autônomos de } \\
\text { avaliação do dos diferentes sistemas de ensino (Ver } \\
\text { Art. } 8 \text { da Lei } n^{\circ} \text { 9394/1996). }\end{array}$ \\
\hline $\begin{array}{l}\text { e) convocação a uma maior } \\
\text { participação dos pais e da } \\
\text { sociedade nos temas relativos à } \\
\text { educação }\end{array}$ & $\begin{array}{l}\text { - Participação dos pais e da sociedade na gestão } \\
\text { da educação a partir de sua participação em } \\
\text { diferentes instâncias colegiadas (Ver Art. } 14 \text { da Lei } \\
n^{\circ} \text { 9394/1996). }\end{array}$ \\
\hline $\begin{array}{l}\text { f) reforço ao papel do setor } \\
\text { privado e não governamental nas } \\
\text { atividades educacionais (decisões } \\
\text { e implementação) }\end{array}$ & $\begin{array}{l}\text { - Estabelecimento de parcerias entre o setor público } \\
\left.\text { e privado (Ver Lei Federal } n^{\circ} 11.079 / 2004\right) \text {. } \\
\text { - Criação de Conselhos Federais, Estaduais e } \\
\text { Municipais de participação e decisão colegiada (Ver } \\
\text { Art. 9, 26, } 36 \text { e } 39 \text { da Lei }{ }^{\circ} \text { 9394/1996). }\end{array}$ \\
\hline $\begin{array}{l}\text { g) mobilização e alocação de } \\
\text { recursos adicionais aos projetos } \\
\text { educacionais }\end{array}$ & $\begin{array}{l}\text { - Criação de Programas e Ações Especiais } \\
\text { especialmente voltados ao Ensino Superior (Ver } \\
\text { informações disponíveis em: http://portal.mec.gov.br/ } \\
\text { sesu-secretaria-de-educacao-superior/programas- } \\
\text { e-acoes). }\end{array}$ \\
\hline $\begin{array}{l}\text { h) ênfase nos aspectos setoriais } \\
\text { (alguns) da educação }\end{array}$ & $\begin{array}{l}\text { - Segmentação do sistemas de ensino em básico, } \\
\text { técnico, tecnológico e profissionalizante com ênfase } \\
\text { na formação na especialização e no atendimento } \\
\text { das necessidades básicas (alfabetização e } \\
\text { letramento), técnica (formação e mão-de-obra para } \\
\text { a indústria), tecnológica (formação de mão-de-obra } \\
\text { especializada e voltada as necessidades regionais) } \\
\text { e superior (voltada a uma formação bacharelesca } \\
\text { e técnica que visa atender as necessidades de } \\
\text { educação superior e de mão-de-obra do mercado) } \\
\text { (Ver Lei nº 9394/1996, em especial, os Art. } 1 \text { e 2). }\end{array}$ \\
\hline
\end{tabular}




\begin{tabular}{|c|c|}
\hline EIXO DE AÇÃO & POLÍTICA/AÇÃO CORRELATA \\
\hline $\begin{array}{l}\text { i) definição de políticas e } \\
\text { estratégias com base em critérios } \\
\text { de análise econômicos. }\end{array}$ & 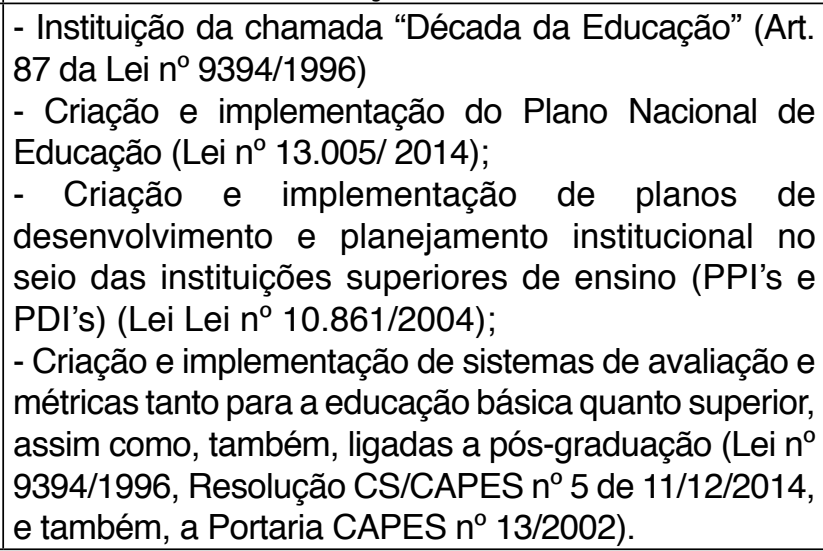 \\
\hline
\end{tabular}

\title{
10. DO PROMETEU LIBERTO: ALGUMAS CONSIDERACÕ̃ES ACERCA DA UNIVERSIDADE E OS DESAFIOS QUE A ESTA SE IMPÕE NO TEMPO PRESENTE
}

\author{
Um dia, numa rua da cidade, eu vi um velhinho sentado na calçada \\ Com uma cuia de esmola e uma viola na mão \\ O povo parou para ouvir, ele agradeceu as moedas \\ $\mathrm{E}$ cantou essa música, que contava uma história \\ Que era mais ou menos assim,,,
}

(Raul Seixas - Eu nasci a dez mil anos atrás - 1976)

Neste quadro geral e de pronto caracterizado como um emaranhado de "portas", "janelas", "entradas", "saídas", "corredores", "escadas", "salas", "subsolos", "sótãos", "cantos", "recantos", "espaços abertos", "espaços fechados", todos partes constituídas e estabelecidas como limites ou aberturas para transformações, ocupações, soluções e saídas, estabelecidas ao longo das últimas décadas do século passado e no início do atual é que somos instados a pensar, mas não só isso, como a exercer as atividades e as responsabilidades da administração e da gestão das instituições educacionais públicas de educação superior, ou seja, das universidades. Certamente temos como guia o discurso que fundamenta e direciona as atividades e funções da universidade: seus objetivos, seus fins, sua natureza, seu caráter social e público.

E, é justamente aí, na sua concepção e acepção que residem os parâmetros e os critérios do seu agir e do seu decidir. Estes, emanados da clareza, do consenso, do peso, do sentido, do significado e a natureza do seu "ser" institucional 
que a faz possuidora de uma identidade única e singular. O que não a torna onipotente ou lhe oferece uma "proteção" superior e/ou "sagrada". Mas, certamente Ihe confere o húmus da universalidade, que enraizada no universo social detém o reconhecimento "orbe et urbi".

Assim, é aí que a autonomia como noção inerente a universidade, ao mesmo tempo que em assim sendo - própria e constitutiva da sua ideia e da sua natureza - se impõe e quando atingida é subtraída na sua efetividade, dando espaço a dicotomia "discurso e prática" onde a aparência dos "ditos" não se revela nos "feitos". Isto, algo manifesto na trajetória histórica das universidades que em busca dessa preterida autonomia tem pensado e repensado a própria instituição e o papel dos gestores públicos nesse processo, como é o caso da reflexão que aqui nos propomos a realizar.

De fato, se partirmos da compreensão de que a universidade é uma instituição social que exprime, de maneira determinada a estrutura e o modo de funcionamento da sociedade como um todo (CHAUí, 2003, p. 5) e que no seu interior ecoam opiniões, atitudes e projetos conflitantes tem-se então que, esta, é, portanto, o espelho das contradições existentes na própria sociedade da qual faz parte de modo que, sua legitimidade, na atualidade, funda-se "na conquista da ideia de autonomia do saber, em face da religião e do Estado" (CHAUÍ, 2003, p. 5).

Isto, algo que se insere no âmbito da tese weberiana da racionalização do mundo onde a ciência assume diante da religião um locus privilegiado enquanto princípio estruturante do mundo. Desta feita, tem-se então que o processo de construção do conhecimento passa a ser guiado por uma lógica própria e reflete as necessidades sociais do seu tempo de modo que, como escreve Chauí (2003, p. 5),

[...] Em outras palavras, sobretudo depois da Revolução Francesa, [tem-se que] a universidade concebe-se a si mesma [ou passou a conceber-se] como uma instituição republicana e, portanto, pública e laica e, em função disso e como corolário dessa concepção de universidade tem-se que [...] a educação e a cultura passaram a ser concebidas como constitutivas da cidadania e, portanto, como direitos dos cidadãos, fazendo com que, além da vocação republicana, a universidade se tornasse também uma instituição social inseparável da ideia de democracia e de democratização do saber: seja para realizar essa ideia, seja para opor-se a ela.

Movimento este que se explicita em falas mais recentes da referida professora da Universidade de São Paulo (CHAUÍ, 2014) quando esta assevera sobre a existência de pelo menos duas tendências que, no interior das universidades públicas, buscam assentar como teses hegemônicas constituidoras de um bloco hegemônico, algo que, pensado em termos gramscianos, 
Pressupõe indubitavelmente que sejam levados em conta os interesses e as tendências dos grupos sobre os quais a hegemonia será exercida, que se forme um certo equilíbrio de compromisso, isto é, que o grupo dirigente faça sacrifícios de ordem econômicacorporativa; mas também indubitável que tais sacrifícios e tal compromisso não podem envolver o essencial, dado que, se a hegemonia é ético-político, não pode deixar de ser também econômica; não pode deixar de ter seu fundamento na função decisiva que o grupo dirigente exerce no núcleo da atividade econômica"(GRAMSCI, 2002, p. 48).

Disto decorre que, que do ponto de vista econômico, a universidade pública brasileira, em termos práticos, sempre serviu aos interesses do Estado de modo que com o passar dos anos seu papel foi sendo redesenhado em função de interesses de Estado e de Governo de modo que, com o tempo a universidade deixou de ser uma instituição social com fins e propósitos definidos a priori e passou a ser uma organização que, na atualidade, apenas presta serviços.

Neste sentido, tem-se que para filósofa paulista estariam em disputa pela hegemonia do campo pelo menos dois entendimentos acerca do papel da universidade. Um de cunho tecnocrático para o qual a administração é percebida e praticada com base nos princípios gerais da administração de modo que não há diferenciação de tratamento entre diferentes organizações, instituições e corporações devendo todos serem regidos pelos mesmos princípios sem considerar suas especificidades. Outro, de caráter humanista que tende a considerar o material humano (pessoas) e os propósitos e fins da universidade como basilares, como seu maior patrimônio, e que se pauta no fato de que a universidade para além de sua função social deve ter autonomia para pensar e eleger suas prioridades sem atrelar-se ao governo. Ou ainda, no que se refere aos serviços que essa oferece, se pautar em modelos de gestão que não visem apenas cumprir os critérios econômicos relacionados a sua eficiência e pedagógicos relacionados a sua eficácia, sem levar em conta sua efetividade, relevância e incidência social.

Posto isto, tem-se que tal mudança no perfil da universidade está inserida em um contexto social específico e totalizante da sociedade como um todo onde sob a égide do capital se observam, segundo Chauí (2014, p.3-4), três fases sucessivas de desenvolvimento da universidade; a) saber: a uma primeira que tomou a universidade como uma instituição funcional; b) uma segunda que a concebe como uma instituição/organização que deve se pautar em resultados; e, c) uma terceira que a percebe como uma organização meramente operacional que cumpre as exigências e atende exclusivamente aos interesses daqueles que são seus mantenedores sob a forma de uma mera prestadora de serviços. 
Neste sentido, ao correlacionar-se a períodos históricos específicos tais etapas de seu desenvolvimento correspondem, a partir de uma perspectiva gramsciana, à hegemonia de determinadas ideias acerca de seu papel/função de modo que para Chauí (2014, p. 5-6), no Brasil:

A universidade funcional, dos anos 70 , foi o prêmio de consolação que a ditadura ofereceu a sua base de sustentação político-ideológica, isto é, a classe média despojada de poder. A ela foram prometidos prestigio e ascensão social por meio do diploma universitário.

\begin{abstract}
A universidade de resultados, dos anos 80 , foi aquela gestada pela etapa anterior, mas trazendo duas novidades. Em primeiro lugar, a expansão para o ensino superior da presença crescente de escolas privadas, encarregadas de continuar alimentando o sonho social da classe média; em segundo lugar, a introdução da ideia de parceria entre as universidades públicas e as empresas privadas.
\end{abstract}

\begin{abstract}
A universidade operacional de nossos dias que difere das formas anteriores [...]. [E, esta,] voltada diretamente para o mercado de trabalho [...]. Regida por contratos de gestão, avaliada por índices de produtividade, calculada para ser flexível, a universidade operacional está estruturada por estratégias e programas de eficácia organizacional e, portanto, pela particularidade e instabilidade dos meios e objetivos.
\end{abstract}

Do exposto tem-se do ponto de vista tecnocrático, como no caso do ponto de vista da norma legal, a universidade é concedida pouca ou nenhuma liberdade e autonomia na medida em que tem sua gestão engessada pelos fins a ela delegados e de seu desempenho no cumprimento de tais metas depende, sobretudo, sua manutenção e sobrevivência.

Já no âmbito da tradição humanista, outras dimensões passam a ser consideradas e a presença de diferentes grupos e visões no interior da gestão passa a ser uma variável a ser considerada. E, então, no âmbito decisório - ou seja, da administração e da gestão - novos arranjos passam a ser produzidos no sentido de se garantir condições mínimas de governabilidade e governança universitárias. Contudo, não é nosso intuito aqui, abrir o "Jarro" ou "Caixa" dada a Pandora por Zeus, para que essa castigasse a humanidade - em razão de sua curiosidade pelo fato de Prometeu ter roubado e dado a estes, o fogo do Monte Olimpo, mas sim, aqui nos ocupar das promessas de um pretenso Prometeu Liberto por (e pela) garantia de uma constitucional autonomia administrativa das instituições de ensino superior. 


\section{REFERÊNCIAS}

Altmann, H. (2002) Influência do Banco Mundial no projeto educacional brasileiro, Educação e Pesquisa, São Paulo, v.28, n.1,p.77-89,jan/jun.2002.

Bordieu, P.; Champagne; P. (1998) Os excluídos do interior. In: BORDIEU, P (Coord.) Miséria do mundo 2 ed. Petrópolis: Vozes.

BRASIL. Constituição (1988). Constituição da República Federativa do Brasil. Brasília, DF: Senado Federal: Centro Gráfico.

Brovetto, Mix, Panizzi. J.M.W. (2003) A educação superior frente a Davos, Porto Alegre, Editora: UFRGS.

Chauí, M. (2003) Seminário - Universidade: Porque e como reformar? Brasília: MEC/SESU.

Chauí, M. (2014) Contra a universidade operacional - A greve de 2014. Disponível em: www.adusp.org.br/files/database/2014/tex_chaui

Corragio, J. L. (1996) Propostas do Banco Mundial para a educação:sentido oculto ou problemas de concepção? In: TOMMASI, L. De. WARDE, J.M; HADDAD,S. (Orgs.) O Banco Mundial e as políticas educacionais, São Paulo:Corteza/Ação Educativa/PUC-SP,. Pp. 75-124.

Ferraz, D.C. (A Autonomia Universitária na Constituição de 05.10.1998'disponível em: http://www.pge.sp.gov.br/centrodeestudos/revistaspge/revista/tes5.htm

Fonseca, M. (1995) O Banco Mundial e a educação: reflexões sobre o caso brasileiro (In) O Banco Mundial e Educação.

Gramsci, A. (2002) Cadernos do Cárcere. Rio de Janeiro: Civilização Brasileira. C3. Volume 3 - Caderno 13.

Hesíodo. P. (1914) In: Theogony: Homeric Hymns, Epic Cycle, Homerica. Loeb Classical Library Volume 57. London: William Heinemann.

Ivashita, N., Bertolleti, S.M.V. (2009) O ensino superior na perspectiva do Banco Mundial: Algumas considerações, IX Congresso Nacional de Educação EDUCERE, III Encontro Sul Brasileiro de Psicopedagogia,- PUCPR.

Panizzi, W.; Meirelles, M. (2014) Em busca das origens: pensando o papel da universidade e seus compromissos com o desenvolvimento local e do país. In: XIV Colóquio Internacional de Gestão Universitária - GIGU, 2014, Praia dos Ingleses. Anais do XIV Colóquio Internacional de Gestão Universitária GIGU. Florianópolis : INPEAU, 2014. Pp. 1-20.

Panizzi, W.; Meirelles, M. (2013) Educando para a diversidade: a Iniciação Científica como uma atividade extra classe. In: MEIRELLES, M.; MOCELIN, 
D.; RAIZER, L.; PEDDE, V.; SCHWEIG, G. R. (Orgs.). Trabalho, Ciência, Cultura, Diversidade. Coleção Olhares Contemporâneos. Porto Alegre, Pp. 321-338.

Panizzi, W. (2006) Universidade para quê? Porto Alegre: Libretos.

Panizzi, W. (2013) O Arauto que anuncia o início de um novo tempo: universidade e mudança social. In: Andifes e os Rumos das Universidades Federais, Brasília, Pp.90 - 102.

Panizzi, W. (2015) Autonomia, governança e governabilidade universitárias: impasses e perspectivas para o século XXI. In: Fórum latino-americano de educação superior (Org.).Marília Morosini. São Carlos: Pixel, 2015.

Panizzi, W. (2004) Universidade pública gratuita de qualidade. Porto Alegre: Editora UFRGS.

Santiago, A.M. (2011) O Banco Mundial e a Gestão da Educação Brasileira: Grandes desafios. Revista de Desenvolvimento Social, Universidade Estadual de Montes Claros - Unimontes. 